\title{
ЦИТОТОКСИЧЕСКИЕ КОМПЛЕКСЫ ОЛОВА (IV) С ЛИГАНДАМИ - МИМЕТИКАМИ ВИТАМИНА Е
}

\section{Е.М. Миронова, Е.А. Никитин, Д.Б. Шпаковский, Ю.А. Грачева}

Химический факультет, Московский государственный университет им. М.В.Ломоносова, 119991, Россия, Москва, Ленинские горы, 1, с. 3.

DOI: 10.19163/MedChemRussia2021-2021-358

E-mail:kamironova2012@yandex.ru

Лекарственная резистентность опухолевой ткани является серьёзным препятствием при лечении онкозаболеваний. В этой связи, поиск новых противораковых препаратов является важной задачей.

Оловоорганические соединения проявляют широкий спектр физиологической активности [1]. Введение в их структуру фрагментов с доказанными цитопротекторными свойствами позволит снизить токсичность соединений для здоровых клеток. 2,6-Диалкилфенолы являются миметиками витамина E и эффективными антиоксидантами. Целью данной работы является синтез оловоорганических комплексов, содержащих фрагмент 2,6-диmрет-бутилфенола. Соединения 1-8 охарактеризованы методами ЯМР-, ИКспектроскопии, MALDI-TOF, рентгеноструктурным и элементным анализом.<smiles></smiles><smiles>NCCCn1ccnc1</smiles>

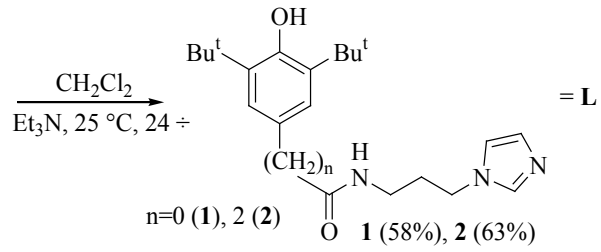

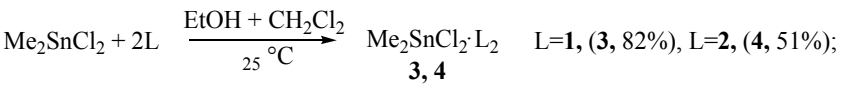

$$
\begin{aligned}
& \begin{array}{cccc}
\mathrm{R}_{3} \mathrm{SnCl}+\mathrm{L} & \mathrm{EtOH}+\mathrm{CH}_{2} \mathrm{Cl}_{2} & \mathrm{R}_{3} \mathrm{SnCl} \cdot \mathrm{L} & \mathbf{R}=\mathrm{Ph}, \mathrm{L}=\mathbf{1},(\mathbf{5}, 54 \%), \mathrm{L}=\mathbf{2},(\mathbf{6}, 73 \%) ; \\
\cline { 2 - 2 } & \mathbf{5 - 8}{ }^{\circ} \mathrm{C} & \mathbf{R}=\mathrm{Me}, \mathrm{L}=\mathbf{1},(\mathbf{7}, 72 \%), \mathrm{L}=\mathbf{2},(\mathbf{8}, 61 \%) ;
\end{array}
\end{aligned}
$$

Антиоксидантные свойства соединений оценены в ДФПГ- и CUPRACтестах, цитотоксичность исследована в МТТ-тесте и на опухолевой ткани, полученной от пациентов. Выявлено соединение-хит 5, проявляющее $\mathrm{IC}_{50}$ B наномолярном диапазоне концентраций. Полученные результаты позволяют предложить исследуемую серию для дальнейших испытаний в качестве перспективных противоопухолевых агентов.

Работа выполнена при финансовой поддержке РФФИ (№ 19-33-90236; № 20-03-00471).

\section{Литература}

[1] E. Milaeva, D. Shpakovsky, Yu. Gracheva, A. Antonenko, T. Ksenofontova, E. Nikitin,

D. Berseneva, Pure and Applied Chemistry. 2020, 92, 1201-1216. 